\title{
Fundamental Study of Dual Fuel on Exhaust Gas Recirculation (EGR) operating with a Diesel Engine
}

\author{
Mohd Hafizil Mat Yasin ${ }^{1, *}$, Perowansa Paruka ${ }^{1}$, Rizalman Mamat ${ }^{2}$, \\ Mohd Hafiz Ali
${ }^{1}$ Mechanical Engineering Department, Politeknik Kota Kinabalu, Jalan Politeknik, 88450 Kota Kinabalu, Sabah
${ }^{2}$ Faculty of Mechanical Engineering, Universiti Malaysia Pahang
E-mail: mohdhafizil80@gmail.com, perowansa@polikk.edu.my, rizalman@ump.edu.my, \\ hafiz@polikk.edu.my
}

\begin{abstract}
Keyword: Exhaust gas recirculation (EGR), liquefied petroleum gas (LPG), emission, diesel engine
\end{abstract}

\begin{abstract}
In this paper, an experimental study evaluating the effect of exhaust gas recirculation (EGR) and liquefied petroleum gas (LPG) onboard systems attached to a single cylinder DI diesel engine running with diesel is presented. Tests were performed at the minimum $(1400 \mathrm{rpm})$ and maximum engine speeds $(4100 \mathrm{rpm})$. The engine were tested under four different operating modes mainly; (a) standard test condition, (b) engine with EGR system, (c) engine with LPG system and (d) the engine with EGR and LPG onboard systems. Parameters that been measured during the tests are percentage of oxygen $\left(\mathrm{O}_{2}\right)$ content, carbon monoxide $(\mathrm{CO})$ emissions, carbon dioxide $\left(\mathrm{CO}_{2}\right)$ and unburned hydrocarbon (UHC) emissions. Results show for the exhaust emissions, the engine with LPG onboard system emits higher CO and UHC emissions for both engine speeds. According to the experimental results it can be concluded that the use of EGR system increased the exhaust gas temperature and $\mathrm{CO}_{2}$ emissions. While the engine with EGR and LPG onboard systems have influenced much on the increase in $\mathrm{CO}$ and UHC emissions for both engine speeds.
\end{abstract}

\section{Introduction}

Exhaust emission from the vehicles are among the main causes that contribute to the air pollution. Smoke emitted from the diesel engine can affected the health problem, air pollution, global warming, acid rain, haze and odour. Exhaust emission generally caused by the fossilized fuel combustion that produce the carbon monoxide $(\mathrm{CO})$, nitrogen oxide (NOx), total hydrocarbon (THC) and soot emissions due to lean stocichiometric combustion, partial oxidation and dirts of fuel and air. Generally the engine and the fuel can be developed and been produced for the minimal emission reduction which can be released without harmful the environment. Exhaust gasses treatment is necessary for the emission reduction but the latest technology still cannot achieve the treatment stage.

Presence of higher nitrogen oxides (NOx) and particulate matter (PM) emission in the diesel engine has been subject of current research for the engine manufacturers to meet the stringent requirements of the enclosure upcoming years with exploring various techniques such as exhaust gas recirculation (EGR), after-treatment, and new modes of combustion. Research work results showed that EGR is one of the most effective methods used in modern engines for reducing NOx emissions $[1,2]$. The concept of exhaust gas recirculation (EGR) has been introduced by HaagenSmith [3] in 1955 when he successfully reduced the smog and oxides of nitrogen in the fuel combustion. Then, Kopa et. al. [4] conducted the engine testing using EGR and found that it helps to reduce the formation levels of NOx in exhaust emission. Currently, United States Environmental Protection Agency (EPA) commissioned EGR as a part of the regulations for heavy-duty diesel engines. 
Application of exhaust gas recirculation (EGR) mostly used for the NOx reduction to decrease the cylinder temperature as it is the main cause for the NOx formation. A study by Ramadhas et al.[5] was engaged to investigate the effect of exhaust gas recirculation (EGR) on reducing the NOx emissions when operating the diesel engine with biodiesel as a fuel. The exhaust gasses were recirculated into the air charge and decreased the cylinder temperature for the NOx reduction. However, this mode has significantly increased the carbon monoxide (CO) and total hydrocarbon (THC) emissions. In addition, liquefied petroleum gas (LPG) was injected and mixed with the fresh air before entering the cylinder for the power improvement. Results showed that the exhaust gas temperature for the engine operating with EGR and LPG is lower as compared to the engine operating without EGR.

Another study conducted by Myung et al.[6] using the SI direct injection engine operating with dual fuel which are gasoline and LPG (liquefied petroleum gas) performed on a chassis dynamometer under various test operating conditions. Results indicated that the engine operating with LPG has reduced the total hydrocarbon (THC) and NOx emissions as well as nano-particles compared to the engine running with gasoline. In addition, $\mathrm{CO}_{2}$ emission has been reduced to the range $4-6 \%$ with the similar engine. However, it is found that the increasing in formaldehyde, acetaldehyde and acrolein compounds in the emission contents when operating with LPG fueled vehicle. This mainly caused by the partial oxidation of butane and propane combustion processes. The study also concluded that the regulated and unregulated emissions are mostly related to the vehicle driving pattern variations and the different composition of the fuels. In this study, the combination effects of exhaust gas recirculation (EGR) and liquefied petroleum gas (LPG) system were investigated on the exhaust emissions include carbon dioxide $\left(\mathrm{CO}_{2}\right)$, carbon monoxide $(\mathrm{CO})$ and unburned hydrocarbons (UHCs). Tests were performed at two different engine speeds mainly; $1400 \mathrm{rpm}$ and $4100 \mathrm{rpm}$ operating with mineral diesel.

\section{Experimental Set Up}

The experimental work was carried out using a Robyn DY-23 single cylinder direct injection diesel engine. This is a naturally aspirated, direct injection diesel engine with a bore of 70 $\mathrm{mm}$, stroke $60 \mathrm{~mm}$. Its injection pressure is more or less set to $191.2 \mathrm{bar}$ and a compression ratio of $21: 1$. It is an air-cooled, low-speed and the maximum power was $3.5 \mathrm{~kW}$ at $3600 \mathrm{rpm}$. More engine details are listed in Table 1.

Table 1: Robyn DY-23 engine specification

\begin{tabular}{lc}
\hline Description & Specification \\
\hline Engine Type & Robyn DY-23 \\
Number of cylinder & 1 \\
Bore x stroke $(\mathrm{mm})$ & $70 \times 60$ \\
Piston displacement $\left(\mathrm{cm}^{3}\right)$ & 230 \\
Maximum output, $\mathrm{HP}(\mathrm{kW}) / \mathrm{rpm}$ & $4.8(3.5) / 3600$ \\
Maximum torque, $\mathrm{kgm}(\mathrm{Nm}) / \mathrm{rpm}$ & $1.07(10.5) / 2200$ \\
\hline
\end{tabular}




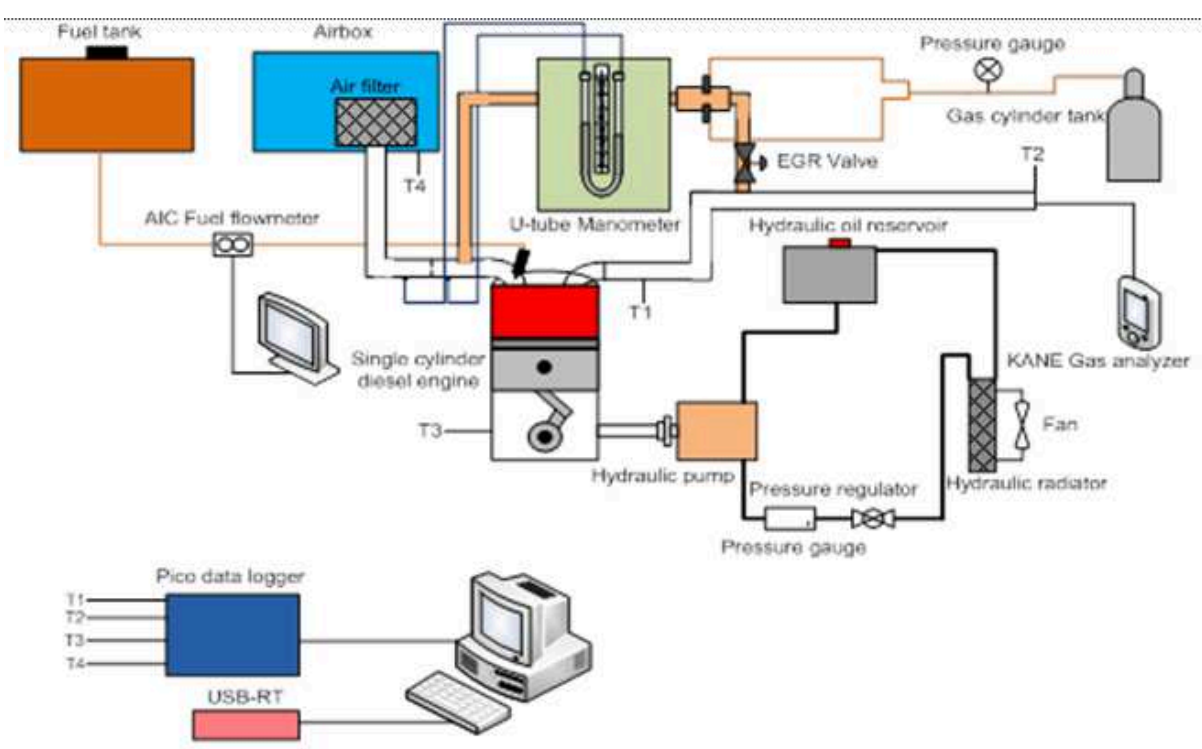

Fig. 1 Engine Instrumentation system set up

Fig. 1 presents the schematic diagram for the experimental apparatus. Engine speeds for the engine was measured by Ono Sokki digital tachometer model HT-3100. K-type thermocouples were attached to the engine oil sump, exhaust extractor and the end of the exhaust pipe for the temperature measurement. 8-Channel temperature indicator from PICO data logger was used as temperature data logger in the experiment. A KANE portable gas analyzer was used to measure the exhaust gases from the engine for the emission measurement. Psycochemical properties of tested mineral diesel can be referred in [7] while the properties for liquefied petroleum gas (LPG) can be referred to Gas Malaysia [8].

In this experimental study, a Robyn DY-23 single cylinder diesel engine was tested under four engine operating modes which are standard (no engine modification), engine with EGR system (exhaust gasses been recirculated into the intake manifold using EGR piping), engine with LPG system (LPG been channeled through the intake manifold, mixing with the fresh air charge) and the engine with combination EGR and LPG systems (EGR and LPG systems been used together). LPG was channeled continuously through the air charge with the line pressure of 0.5 bar. Tests were performed at two different engine speeds mainly; $1400 \mathrm{rpm}$ and $4100 \mathrm{rpm}$ operating with diesel as a baseline fuel. Before the tests are performed, the engine was running for almost half an hour to reach the steady state condition and the engine oil temperature has reached over $80{ }^{\circ} \mathrm{C}$. Then, the tests for each different engine condition were conducted five times to assure the reliability and the accuracy of the measured results.

\section{Results and Discussion}

Sufficient oxygen content produces lean combustion in the cylinder when mixing with the fuel that been injected through the cylinder at the considerate time series. The lack of oxygen is responsible for reduced oxidation rate, which leads to incomplete combustion, hence produces higher unburned hydrocarbon (UHC) emissions. 

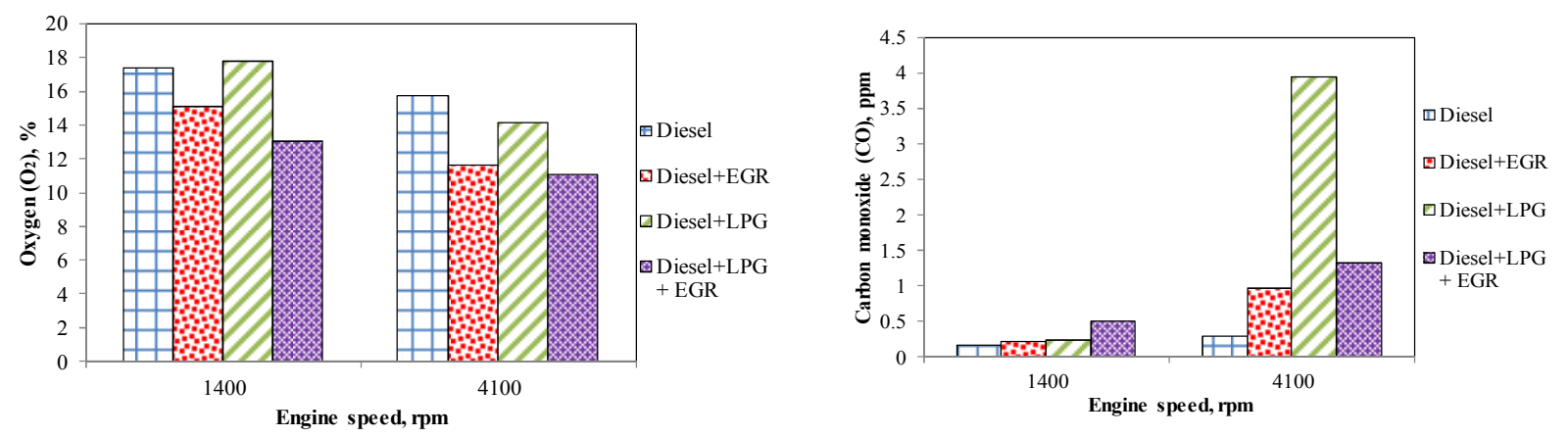

Fig. 2 Variations of oxygen $\left(\mathrm{O}_{2}\right)$ content corresponding to the engine speed

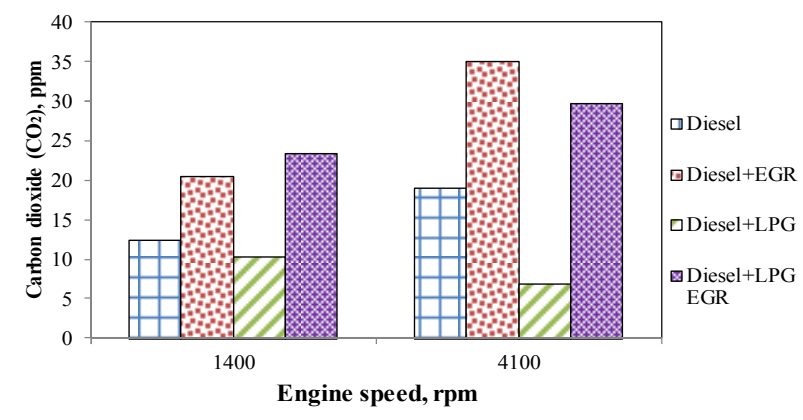

Fig. 3 Variations of carbon monoxide (CO) content corresponding to the engine speed

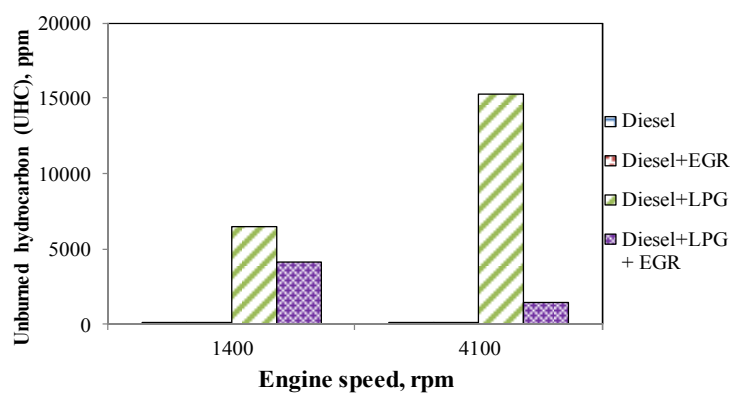

Fig. 4 Variations of carbon dioxide $\left(\mathrm{CO}_{2}\right)$ content corresponding to the engine speed

Fig. 5 Variations of unburned $\mathrm{HC}$ (Hydrocarbon) emission content corresponding to the engine speed

Fig. 2 shows the variations of oxygen content percentage under four test modes. It is noticed that at the minimum engine speed, engine with standard engine test condition and the engine with LPG system have similar percentage of oxygen content compared to other two different engine test modes. However, the engine with standard engine test condition has surpassed the engine with LPG system at the maximum engine speed as well as other two engine test modes. Generally, diesel engines operate with lean mixtures and hence the $\mathrm{CO}$ emission would be low. $\mathrm{CO}$ is predominantly formed due to the lack of oxygen. Fig. 3 depicts the variations of carbon monoxide (CO) emission with diesel operating with four test modes. It is noticed that the engine with EGR and LPG systems has higher $\mathrm{CO}$ emission compared to other engine test modes. It is mainly attributed by some of the oxygen present in the inlet charge is replaced with recirculates exhaust gas that causes incomplete combustion.

Carbon dioxide $\left(\mathrm{CO}_{2}\right)$ is a principal constituent of exhaust gas recirculation. The nature of $\mathrm{CO}_{2}$ is higher with heat capacity and it serves as a heat absorbing agent during the combustion, which reduces the peak temperature in the combustion chamber. Fig. 4 presents the variations of $\mathrm{CO}_{2}$ under four engine test modes. It is observed that the engine with EGR and LPG systems has higher $\mathrm{CO}_{2}$ emission compared to other three test modes at the minimum engine speed. On the other hand, at the maximum engine speed, the engine with EGR system and the engine with EGR and LPG systems have similar amounts of $\mathrm{CO}_{2}$ emission. This scenario explains that with the addition of previous exhaust gas been circulated back into the intake, mix with the fresh air and burn with the fuel has produced more $\mathrm{CO}_{2}$.

Unburned hydrocarbon emissions consist of fuel that is incompletely burned. The UHC variation follows a close trend with increase in EGR resulting in increase in $\mathrm{HC}$ emission. Variations of UHC emissions are depicted in Fig. 5 under four test modes. It is clearly noticed that the engine with LPG system has the highest UHC emissions overall for both minimum and maximum engine speeds. The increase in unburned hydrocarbon with the adaptation of the engine 
with LPG system is due to the reduction of oxygen in the inlet charge and the additional of the second fuel which is liquefied petroleum gas (LPG) into the cylinder.

\section{Conclusion}

In this paper, an experimental study was conducted to evaluate the effects of exhaust gas recirculation (EGR) and liquefied petroleum gas (LPG) onboard systems on the exhaust emissions in a diesel engine operating with diesel. From the study carried out the following conclusions may be drawn:

i. Standard engine test condition has better percentage of oxygen content.

ii. The engine with LPG onboard system produces more CO and UHC emissions operating at minimum and engine speeds.

\section{Acknowledgements}

The authors would like to thank Ministry of Education and Polytechnic Management Department for providing the FRGS grant (FRGS/1/2014/TK01/JPP/03/1) to fund the research.

\section{References}

[1] Z. Chen, J. Liu, Z. Wu, and C. Lee, "Effects of port fuel injection (PFI) of n-butanol and EGR on combustion and emissions of a direct injection diesel engine," Energy Conversion and Management, vol. 76, pp. 725-731, 2013.

[2] Y. Basavarajappa and N. Banapurmath, "Effect of Exhaust Gas Recirculation on the Performance and Emissions of a Dual Fuel Engine Operated on CNG-Biodiesel-Ethanol Blends," International Journal of Engineering, vol. 2, 2013.

[3] M. M. F. Haagen-Smit, "Automobile Exhaust and Ozone Formation," presented at the SAE Golden Anniversary Meeting, Detroit, Michigan, January 1955.

[4] R. D. Kopa, and H. Kimura, "Exhaust GasRecirculation as a Method of Nitrogen Oxides Control in an Internal Combustion Engine," presented at the APCA 53rd Annual Meeting, Cincinnati, Ohio, May 1960.

[5] A. Ramadhas, S. Jayaraj, and C. Muraleedharan, "Performance and emission studies on biodiesel-liquefied petroleum gas dual fuel engine with exhaust gas recirculation," Journal of Renewable and Sustainable Energy, vol. 2, p. 013109, 2010.

[6] C.-L. Myung, K. Choi, J. Kim, Y. Lim, J. Lee, and S. Park, "Comparative study of regulated and unregulated toxic emissions characteristics from a spark ignition direct injection lightduty vehicle fueled with gasoline and liquid phase LPG (liquefied petroleum gas)," Energy, 2012.

[7] R. M. M.H. Mat Yasin, A. F. Yusop, R. Rahim, A. Aziz, L. A. Shah, "Fuel Physical Characteristics of Biodiesel Blend Fuels with Alcohol as Additives," in Malaysian Technical Universities Conference on Engineering \& Technology (MUCET 2012), Kangar Perlis, 2012, pp. 719-722.

[8] B. GasMalaysia, "Liquefied Petroleum Gas (LPG) Chemical Safety Data Sheet," in Physical and Chemical Properties, ed. Selangor, Malaysia, 2011. 